\title{
Unsaturated Flow in Hydrologic Modeling
}

Theory and Practice 


\section{NATO ASI Series}

\section{Advanced Sclence Institutes Series}

A Series presenting the results of activities sponsored by the NATO Science Committee, which aims at the dissemination of advanced scientific and technological knowledge, with a view to strengthening links between scientific communities.

The Series is published by an international board of publishers in conjunction with the NATO Scientific Affairs Division
A Llfe Sclences
B Physics
C Mathematical and Physical Sclences
D Behavloural and Soclal Sclences
E Applled Sclences
F Computer and Systems Sclences
G Ecological Sciences
H Cell Biology

Plenum Publishing Corporation

London and New York

Kluwer Academic Publishers

Dordrecht, Boston and London

Springer-Verlag

Berlin, Heidelberg, New York, London, Paris and Tokyo

Series C: Mathematical and Physical Sclences - Vol. 275 


\section{Unsaturated Flow in Hydrologic Modeling Theory and Practice}

edited by

\section{H. J. Morel-Seytoux}

Department of Civil Engineering,

Colorado State University,

Fort Collins, U.S.A.

\section{Kluwer Academic Publishers}

Dordrecht / Boston / London

Published in cooperation with NATO Scientific Affairs Division 
Proceedings of the NATO Advanced Research Workshop on

Unsaturated Flow in Hydrologic Modelling Theory and Practice

Arles, France

13-17 June 1988

\section{Library of Congress Cataloging in Publication Data}

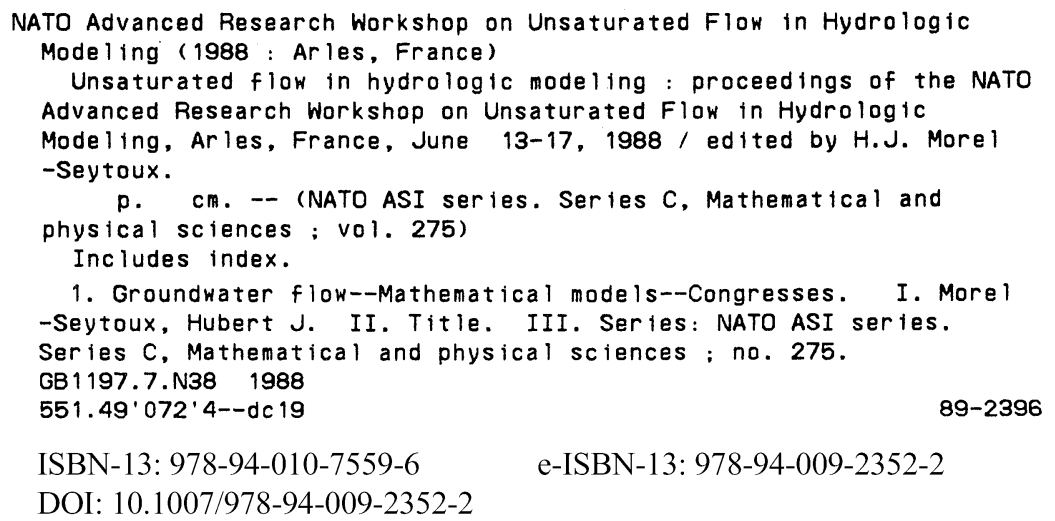

Published by Kluwer Academic Publishers,

P.O. Box 17, 3300 AA Dordrecht, The Netherlands.

Kluwer Academic Publishers incorporates the publishing programmes of

D. Reidel, Martinus Nijhoff, Dr W. Junk and MTP Press.

Sold and distributed in the U.S.A. and Canada

by Kluwer Academic Publishers,

101 Philip Drive, Norwell, MA 02061, U.S.A.

In all other countries, sold and distributed

by Kluwer Academic Publishers Group,

P.O. Box 322, 3300 AH Dordrecht, The Netherlands.

Printed on acid free paper

\section{All Rights Reserved}

(C) 1989 by Kluwer Academic Publishers

Softcover reprint of the hardcover 1st edition 1989

No part of the material protected by this copyright notice may be reproduced or utilized in any form or by any means, electronic or mechanical, including photocopying, recording or by any information storage and retrieval system, without written permission from the copyright owner. 
This book contains the proceedings of a NATO Advanced Research Workshop held within the programme of activities of the NATO Special Programme on Global Transport Mechanisms in the Geo-Sciences running from 1983 to 1988 as part of the activities of the NATO Science Committee.

Other books previously published as a result of the activities of the Special Programme are:

BUAT-MENARD, P. (Ed.) - The Role of Air-Sea Exchange in Geochemical Cycling (C185) 1986

CAZENAVE, A. (Ed.) - Earth Rotation: Solved and Unsolved Problems (C187) 1986

WILLEBRAND, J. and ANDERSON, D. L. T. (Eds.) - Large-Scale Transport Processes in Oceans and Atmosphere (C190) 1986

NICOLIS, C. and NICOLIS, G. (Eds.) - Irreversible Phenomena and Dynamical Systems Analysis in Geosciences (C192) 1986

PARSONS, I. (Ed.) - Origins of Igneous Layering (C196) 1987

LOPER, E. (Ed.) - Structure and Dynamics of Partially Solidified Systems (E125) 1987

VAUGHAN, R. A. (Ed.) - Remote Sensing Applications in Meteorology and Climatology (C201) 1987

BERGER, W. H. and LABEYRIE, L. D. (Eds.) - Abrupt Climatic Change - Evidence and Implications (C216) 1987

VISCONTI, G. and GARCIA, R. (Eds.) - Transport Processes in the Middle Atmosphere (C213) 1987

SIMMERS, I. (Ed.) - Estimation of Natural Recharge of Groundwater (C222) 1987

HELGESON, H. C. (Ed.) - Chemical Transport in Metasomatic Processes (C218) 1987

CUSTODIO, E., GURGUI, A. and LOBO FERREIRA, J. P. (Eds.) - Groundwater Flow and Quality Modelling (C224) 1987

ISAKSEN, I. S. A. (Ed.) - Tropospheric Ozone (C227) 1988

SCHLESINGER, M. E. (Ed.) - Physically-Based Modelling and Simulation of Climate and Climatic Change 2 vols. (C243) 1988

UNSWORTH, M. H. and FOWLER, D. (Eds.) - Acid Deposition at High Elevation Sites (C252) 1988

KISSEL, C. and LAY, C. (Eds.) - Paleomagnetic Rotations and Continental Deformation (C254) 1988

HART, S. R. and GULEN, L. (Eds.) - Crust/Mantle Recycling at Subduction Zones (C258) 1989

GREGERSEN, S. and BASHAM, P. (Eds.) - Earthquakes at North-Atlantic Passive Margins: Neotectonics and Postglacial Rebound (C266) 1989. 


\section{DEDICATION}

This book is dedicated to the Institut de Genie Rural, Hydrologie et Amenagement (IGRHAM), of the Ecole Polytechnique Federale of Lausanne, to its director Professor André Musy and to all members of that most hospitable, young and dynamic Institute.

I would like to thank Professor Vittoz, President of the Ecole Polytechnique Federale de Lausanne (E.P.F.L.) who made my visit as Professeur Invite possible during the calendar year 1987. The support of the E.P.F.L. made the organization, planning and production of this book a relatively easy and certainly enjoyable task. 
TABLE OF CONTENTS

Preface

Part 1. PERSPECTIVE AND FUNDAMENTALS OF UNSATURATED FLOW

L. W. De Backer

Background Concepts and Principles

J. G. Ganoulis

Multiphase Flow in Porous Media: Description at the Pore and Macroscopic Scale

M. Vauclin

Flow of Water and Air in Soils: Theoretical and

Experimental Aspects

Part 2. COMPONENTS IN THE DESCRIPTION OF UNSATURATED FLOW

J. Y. Parlange and R. Haverkamp Infiltration and Ponding Time

R. J. Charbeneau Liquid Moisture Redistribution: Hydrologic Simulation and Spatial Variability

A. Musy, M. Soutter and P. Perrochet

Evaluation of the Hydrological Response of a Drainage Network

K. Beven

Interflow

P. C. D. Milly

Unsaturated Flow Induced by Evaporation and Transpiration

H. J. Morel-Seytoux and C. Miracapillo

Prediction of Water Table Mound Development and Aquifer

Recharge from an Infiltrating Area

Part 3. PARAMETERS ESTIMATION AND NUMERICAL TECHNIQUES

W. J. Rawls and D. L. Brakensiek

Estimation of Soil Water Retention and Hydraulic Properties

G. A. Schultz

Remote Sensing of Watershed Characteristics and Rainfall Input 
T. N. Narasimhan

Numerical Simulation of Richards Equation: Current

Approaches and an Alternate Perspective

Part 4. TREATMENT OF UNSATURATED ZONE IN HYDROLOGIC MODELS

D. M. Goldman

Loss Rate Representation in the HEC-1 Watershed Model

R. E. Smith and V. A. Ferreira

Comparative Evaluation of Unsaturated Flow Methods in Selected USDA Simulation Models

H. J. Morel-Seytoux and S. Al Hassoun

The Unsaturated Components of SWATCH: A Multiprocess Watershed Model for Runoff Generation and Routing

E. Ledoux, G. Girard, G. de Marsily, J. P. Villeneuve and

$\mathrm{J}$. Deschenes

Spatially Distributed Modeling: Conceptual Approach, Coupling Surface Water and Groundwater

P. Matias, F. N. Correia and L. S. Pereira

Influence of Spatial Variability of Saturated Hydraulic

Conductivity on the Infiltration Process

Part 5. MISCELLANEOUS

I. L. López-Baković and J. L. Nieber Analytic Steady-State Solution to One-Dimensional Unsaturated Water Flow in Layered Soils

P. D. Jenssen

The Constant Head Percolation Test-Improved Equipment and Possibilities of Assessing the Saturated Hydraulic Conductivity

B. E. Sleep and J. F. Sykes Mobility of Residual Phase Organics in the Vadose Zone

T. K. Karalis

The Movement of Water in Swelling Clays

Subject Index

General List of Symbols 
This volume certainly is a Conference Proceedings, the Proceedings of the NATO Advanced Research Workshop (ARW) on "Unsaturated Flow in Hydrologic Modeling" held at "Les Villages du Soleil" near Arles, France from June 13 to 17, 1988. Let me therefore acknowledge properly, at the very beginning, the gratitude of all the participants to the NATO Science Committee for its generous support and worthwhile goal of bringing together scientists of many countries to communicate and share their experiences. Particular thanks are extended to the director of the program, Dr. Luis Vega da Cunha for his interest and understanding.

On the other hand this volume is also, and probably more so, a Textbook that fills a gap in the field of unsaturated flow. Many treatises on the subject present the theory in its different aspects. Hardly any explain in details how the different pieces can be put together to address realistic problems at the basin scale. The various invited contributions to the ARW were structured in a subject progression much as chapters are organized in a book. The intent of the ARW was to assess the current state of knowledge in "Unsaturated Flow" and its use in "Hydrologic Modeling Practice". In a sense the interest in fundamentals of unsaturated flow in this ARW was not just for the sake of knowledge but also and primarily for the sake of action. Can such fundamental knowledge be utilized for better management of the water resource? was the basic question. If the answer is affirmative, albeit in a qualified way, how can it be done and what are the road blocks to such utilization? The book should be useful to hydrologists, soil physicists and environmental scientists, professionals as well as students, mostly graduate, who wish to go beyond the usual grasp of the basics and understand how such fundamental knowledge has been and can be shaped into practical tools for assessment and management.

Research in hydrology is needed across a wide range of scales, scanning an extreme spectrum which starts with fundamental research on physical processes at the microscopic (or say Darcy) scale to end with applied research on methodology (tools) for solution of large-scale (field) management problems for basins covering millions of square miles. It is good for researchers to carry investigations at scales which are orders of magnitude apart in order to gain perspective. Ultimately the fundamental microscopic research must be integrated into practical river basin management. The successful passage from a smaller to a larger scale requires: enlightened simplification, integration in many senses that is (1) in time, (2) in space, (3) in an expectation sense and (4) in a process sense, and finally enlightened coupling. At any level successful research for the good of the scientific community requires a long march that proceeds with many steps generally with the gradation: (1) basic understanding,

formulation, (3) solution, (4) verification, (5) investigation, 
simplification, (7) insertion, and (8) vulgarization. For concreteness I shall try to illustrate these steps for the case of infiltration.

\section{A. BASIC UNDERSTANDING}

Fortunately for modern day researchers, the basic understanding was initiated when the concept of hydraulic head was introduced (Bernouilli) and when the basic empirical law for water flow in sand was brought in evidence by Darcy. A bold step was taken by Muskat to generalize Darcy's law to immiscible multiphase flow. However, one should recognize that the catchy naming of a characteristic such as "relative permeability" of itself sheds no light on the nature of the "fudge" factor that it is. There is no doubt that more fundamental research is needed to understand "relatively permeability" and "capillary pressure" specially when more than two phases are present (e.g. water, air and oil) in addition to the porous medium. From a practical standpoint however, is such knowledge required to predict losses in order to forecast the runoff in a watershed on a rainy day?

\section{B. FORMULATION}

The manipulation of Darcy's law with the principle of conservation of mass and a few assumptions, briefly mentioned in some textbooks, has led to the accepted Richards' equation for the description of water flow in the unsaturated zone. There have been arguments over the "best" formulation of such equation, namely whether the dependent variable should be water content or water pressure or the so-called Kirchoff potential. There have been few rational and comprehensive studies made in this regard and ultimately the question that really needs to be addressed is: is there an "entry pressure" at the parcel scale (i.e. next magnitude beyond the narrow laboratory soil column)? Even if the slope of capillary pressure with water content is truly infinite at saturation, can it be represented by a very, very steep gradient? If not, can the problem be really well-posed?

Part 1 of this book "PERSPECTIVE AND FUNDAMENTALS" consists of 3 chapters by de Backer, Ganoulis and Vauclin, respectively. The authors review the basic known physical principles that govern unsaturated flow and the limitations in our knowledge of the subject. De Backer puts it in perspective. "In the context of actual managerial problems where a lot of projects are experiencing failure with considerable losses, there is an increasing need for a structured approach to problem analysis and solving" (this volume, p. 5). This volume responds to a need for a rational and practical description of the vadose zone phenomena.

Ganoulis provides a useful and lucid description of multiphase flow in porous media at the pore scale and the manner in which such knowledge can be aggregated to "understand the flow phenomena at the macroscopic scale. For the case of single-phase flow, the validity of Darcy's law has been explained. Darcy's law is remarkably linear not because the local nonlinear terms are small at low Reynolds' numbers but mainly because of the fact that the local nonlinear momentum terms 
take equal and opposite values in the converging and diverging sections of the flow" (this volume, p. 44).

Starting immediately with the Darcy scale (in the planned progression that was the design for this book) Vauclin shows how the movement of water and air can be formulated at the macroscopic level and how a variety of problems (such as imbibition or infiltration), with a few simplifications, can be solved by this formulation. Vauclin shows that the two-phase formulation contains as subcases Richards' equation (this volume, p. 61) and Philip's flux-concentration concept (ibidem, p. 69). Vauclin does warn that his chapter is based on acceptance of Darcy's law to represent water flow. "However, nonDarcian flows are likely expected during nonsaturated conditions in structured soil ..., in such systems presenting relatively large and more or less continuous voids such as interaggregate pores, earthworm holes, drying cracks, decayed root channels" (ibid., p. 85).

Must we then wait till a complete understanding of the phenomena is available in order to forecast the runoff in a watershed on a rainy day? The answer is no for several reasons. First, for practical reasons "empiricism will remain the rule for quite a while ... to solve the urgent problems or to prevent those to come that we know will be worse" (de Backer, p. 10). Second one would have to wait for ever. "Recognition of a concept of unknowability of the system implies that there can be no ultimate validation of any model structure used to represent that structure .... The impossibility of validation implies that the notion of an optimal model and set of parameter values should be rejected in favor of a more relativist view" (Beven, p. 210 and 212). Finally practitioners seem to feel that simple models can be quite adequate. For example "the Green-Ampt method is not without theoretical difficulties which are well documented. However, these difficulties are probably dwarfed by the overwhelming problem of estimating model parameters in an ungaged analysis" (Goldman, p. 355).

\section{SOLUTION}

Ultimately the physically derived governing partial differential equation must be solved subject to meaningful boundary conditions. The equation is "integrated", a language that communicates the feeling that knowledge of basic laws at a point and at a given moment is not very useful. The answers must be brought to a meaningful larger scale of practical interest. The solution will depend upon the domain of integration and upon the boundary conditions (including initial, $t=0$ is a boundary of the time axis). Under a rainfall condition over a short closed soil column in which air will compress as water infiltrates, what is the boundary condition at the soil surface after ponding has occurred? It is tempting to assume that surface water content is at saturation and that surface air pressure equals atmospheric pressure plus ponded depth plus entry pressure. But there must be room for air to escape and thus water content cannot be at saturation. Is this air escape continuous or pulsative? What is the relation between that pulsative time scale and the Darcy space scale at which the capillary pressures and relative permeabilities are defined? 


\section{VERIFICATION}

There are enough doubts cast about the previous steps that one wishes to verify the solutions, numerical or analytical, against the "real" thing, usually laboratory experiments of which there are only few and the number of which cannot come even close to the number of combinations of practical interest.

\section{E. INVESTIGATION}

Once the solution verified at least for a few combinations of circumstances, many numerical investigations can be carried out to answer many relational questions: how does ponding time relate to rainfall intensity? How does initial water content affect ponding time? How does a break in rainfall pattern affect ponding time? etc. The computer provides today a wonderful apparatus for experimentation. However, by that time in the process the researcher usually seems to have run out of steam and few investigations are done and apparently even fewer reported.

\section{F. SIMPLIFICATION}

Clearly if it takes about $\$ 50$ on the computer to generate a numerical solution of Richard's equation for twenty minutes of real time, such a model cannot be incorporated in an operational watershed model to forecast runoff on a day to day basis. Certainly infiltration is important but it is only one among many components in a catchment model. Much simpler procedures must be developed that are cheaper by at least 2 or 3 orders of magnitude. The simpler procedures must be tested against bench mark solutions and if necessary corrected before they are generally and routinely used.

Part 2 "COMPONENTS" looks at methods to describe in a simple yet physical manner the phenomena of infiltration, moisture redistribution, drainage, interflow, evapotranspiration and aquifer recharge. The book progression is now one of looking at deeper and deeper horizons into the soil, from infiltration at the upper boundary of the vadose zone to aquifer recharge at the lower boundary of the unsaturated zone. It is clear that the separation between these phenomena is mostly conceptual as they tend to occur simultaneously and in various combinations. The separation is useful in the problem analysis phase in order to develop modular parts of an eventual watershed model, provided that in the analysis the goal of integration remains in sight.

Parlange and Haverkamp make a case for the use of physically based and rigorously derived solutions for the problem of infiltration. They show that with empirical or highly simplified equations such as Horton's and Green-Ampt's, the parameters are not intrinsic to the concerned soil but must vary depending upon the boundary or initial conditions and must change with time in the course of one infiltration in order to provide a good match with a bench mark solution. Thus estimates of the parameters under one set of circumstances are not very useful for prediction under a different set of circumstances. 
Charbeneau provides simple solutions for the problem of liquid moisture redistribution, a very important one to enable watershed models to predict the recovery in infiltration capacity between storms. Whereas Ganoulis combined the laws of physics and of chance at the pore scale (this volume, p. 39) to explain the nature of capillary pressure curves and the phenomenon of hysteresis, Charbeneau (this volume, p. 152) combines these laws at the Darcy scale to relate the variability of the prediction of say water content at a given depth to the random variability of hydraulic conductivity.

Musy, Soutter and Perrochet provide a dual analysis of the accelerated hydrologic response of a rural watershed due to the presence of a drainage network. Infiltrated water is intercepted and flows as underground runoff through the drains, contributing a much faster response to streamflow than if it only stimulated the aquifer to respond. In a way their description of the drainage system but in the context of a random distribution of natural pipes can provide answers to the questions raised by Beven regarding the mechanisms of rapid subsurface runoff.

In a key chapter Beven summarizes the evidence that puts the Hortonian concept for runoff generation to trial. "Indeed ... it is unlikely that Horton would have often observed surface runoff in his hydrological laboratory in his back garden in Voorheesville, New York" (this volume, p. 192). The verdict is clear but the new paradigm era will be fraught with difficulties. However Beven suggests an appealing "likelihood approach to provide a suitable framework for the planning and analysis of such studies, including the interflow process" (p. 212).

The next chapter by Milly provides the background and justification for simple "approximate techniques for linking together in time the analytical description of individual events" (p. 221) i.e. events with simple initial conditions and steady boundary conditions, of themselves unsuitable to represent the usual transient nature of the boundary conditions (excitations such as e.g. solar radiation). Milly provides a good example of ingenuous analysis through which a more complex situation can be handled readily within the framework of a simpler situation. "Thus the solutions discussed in the previous sections apply also to problems of isothermal vapor diffusion provided $\mathrm{K}_{\mathrm{w}}$ is replaced by $\mathrm{K}_{\mathrm{w}}{ }^{\prime \prime}$ (this volume, $\mathrm{p}$. 228). As Charbeneau, Milly also shows how to combine the physical approach with a stochastic analysis.

The problem of aquifer recharge addressed by Morel-Seytoux and Miracapillo is the subject of the last chapter in Part 2 "COMPONENTS". It becomes clear in this chapter that a discussion of aquifer recharge in isolation from the subjects of infiltration and redistribution would be misleading. Charbeneau, Beven and Milly implied as much in their respective chapters. However to force oneself to analyze each component individually is a necessary step. In isolation the problem analysis for each component does not look so formidable. Once it is accomplished, all that remains is to discover a clever way for the coupling of the components. Morel-Seytoux and Miracapillo's chapter is thus an exercise in coupling individual existing solutions. They utilize a rectangular profile model for infiltration or redistribution, essentially identical to the one described by Charbeneau, but they 
incorporate the "downstream" effect of a "receiving" dynamic water table responding to that recharge (or eventually to exogeneous lateral influences). There is a coupling of two unsaturated fronts in the unsaturated zone, one descending unsaturated wetting front and an ascending saturating one. There is a coupling in the saturated zone of an essentially vertical flow with a Dupuit-Forchheimer essentially horizontal flow. The solution of a complex overall two or threedimensional, unsaturated-saturated flow problem is reduced to an assemblage of eminently simple individual solutions. De Backer's recommendation for a "structured approach to problem analysis" was certainly well heeded. The needed successive steps of solution, investigation, simplification and verification were very carefully followed. "The prediction ... is truly a verification of the method as none of the drainage phase observations were used for the calibration in the rising phase. The fit to the observations is clearly excellent" (this volume, p. 258).

All the chapters thus far discussed could have started with the qualification: "Given the knowledge of the soil characteristics, their spatial and temporal variability, etc." or "In the beginning there was a saturated hydraulic conductivity..." . Reality is an altogether different matter. Part 3 explores the method of estimation of such characteristics in terms of more readily available measurements.

Rawls and Brakensiek provide a wealth of relations between wetting front suction (alias effective capillary drive) or saturated hydraulic conductivity with more mundane quantities such as $\&$ sand, $\&$ clay, etc. They provide information on the influence of coarse fragments, frozen ground, surface crust, and agricultural or rangeland practices on the hydraulic and retention properties. For the practitioner this chapter may be the most valuable contribution in the book. Theoreticians will welcome it too.

Remote sensing is a promising avenue for the spatially integrated description of watershed characteristics. Schultz reviews the state of the art in this subject. "In the nineties impressive new RS programs will be started by NASA, ESA and other satellite operating agencies... Hydrologists have great hopes for the potential of microwave sensors to be flown in satellites ... for better ways to estimate rainfall, evapotranspiration and soil moisture" (this volume, p. 321).

Only one chapter in this book is dedicated to an assessment of numerical techniques for the solution of Richards' equation. Actually Narasimhan does not cover the basic well-known numerical principles underlying the integrated finite differences or finite elements techniques. Many monographs present this material. Instead in a very inquisitive manner Narasimhan exposes the complacency with which this subject is usually treated. He shows quite convincingly that contrary to accepted notions not only pressure head is an unknown but also the local flow geometry. "The difficulties inherent in the numerical simulation. of Richards equation stem from neglecting the role of local flow geometry in determining the conductances and capacitances, as well as from a failure to recognize that in the general nonlinear case the flux law is an implicit statement" (this volume, p. 339). Incidentally though to resolve a different type of numerical problem, Musy, Soutter and Perrochet propose a new formulation for a unified governing equation for both the unsaturated and saturated zones (Musy et al., this volume, p. 175). 
The simpler procedures must be inserted as modular parts of the complex models. In spite of the existence of such simple procedures many models still rely on very old approaches (e.g. the $\phi$-index method) and as such are forever subject to their inherent limitations. Why is this process of insertion so slow?

\section{H. VULGARIZATION}

The researchers at the frontier of their particular technology should attempt to reach the common people through their simple ("vulgar") language. At the time this workshop was proposed there was not one introductory text in general hydrology that introduced the concept of ponding time, i.e. the time at which rainfall ceases to fully move into the soil and infiltration starts to proceed at capacity. The extremely simple Mein and Larson formula was not mentioned at all.

Part 4 addresses these final steps of insertion and vulgarization. Five chapters review the performance of existing and operational watershed models.

Goldman reviews the capabilities of the model HEC-1. The chapter focuses on the available options for description of loss rates: GreenAmpt, Holtan, SCS, initial and uniform loss rate and exponential loss rate methods. "The loss rate methods used in HEC-1 could be categorized as either empirical or physically based. However, an alternative categorization has been chosen where the loss rate methods will be categorized based on whether or not the methods are best suited to ungaged or gaged watershed analysis" (this volume, p. 345). This distinction is quite germane and practical. One general conclusion is stated: "It is much more difficult to estimate the loss rates than the routing parameters" (ibidem, p. 377). "The most difficult parameters to regionalize are loss rates. However, loss rates are rarely, if ever, regionalized because it is difficult to relate loss rates to basin characteristics... In any case research could be used in finding ways of estimating loss rate parameters on a regional scale" (ibid., p. 387).

Smith and Ferreira compare thoroughly four one-dimensional models in current use by the United States Department of Agriculture. The four models display a gradation of treatment of the unsaturated zone from a simple conceptual linked-storage approach to a sophisticated numerical solution of the pressure-based Richards equation. Though fair comparisons of this type are always difficult, Smith and Ferreira draw nevertheless some general conclusions. "While Richards' equation has been demonstrated consistently in the laboratory to represent the behavior of an ideal, homogeneous soil, and it is clear that real soils have considerable variation, use of a model which ignores soil physics should be justified by its ability to treat field (heterogeneous) soils as well as or better than Richards' equation. This has not been shown" (this volume, p. 411). They point out that some of the models were not adequately documented (stage of vulgarization) and that it was necessary at times to contact a model developer in order to run the model. They also indicate that a great number of numerical 
difficulties were encountered, some of which can probably be traced to the problems mentioned by Narasimhan (this volume, p. 330).

The model SWATCH presented by Morel-Seytoux and Al Hassoun is not limited like HEC-1 to single events (Goldman, this volume, p. 346). It is a fully distributed multi-process model that attempts to represent in a physical manner all the runoff-generation mechanisms discussed by Beven (this volume, p. 194). One distinctive feature of SWATCH is its ability to predict infiltration capacity recovery between storms. This is well displayed on a verification run for the Santa Marta watershed in Portugal. The study of the Turner Creek basin in Georgia illustrates convincingly the ability of the model to reproduce a runoff hydrograph which at $80 \%$ is generated by interflow. However one success should not blind Morel-Seytoux and Al Hassoun to ignore Cassandra's warnings (Beven, this volume, p. 211).

Ledoux, Girard, de Marsily, Villeneuve and Deschenes present the MC mode1 ("Modelle Couple" i.e. Coupled Mode1). The tendencies of many watershed models is to emphasize the surface hydrology and treat casually the groundwater as a sink, or vice versa. The great merit of that model is to demonstrate that it is not necessary to sacrifice either description. "The application of the MC model discussed in this chapter demonstrates how its design, and, more specifically, its means of discretization using nested square meshes of variable sizes, make it a very flexible tool which can be adapted to various hydrological situations and modeling scales. ... it is possible to obtain a reliable basis for computing river discharge (this volume, p. 451).

The last chapter in Part 4 by Matias, Correia and Pereira discusses the use of the watershed model OMEGA to investigate the influence of spatial variability on catchment discharges.

At the ARW in Arles there were poster sessions by a number of participants. Due to their manifest quality, the organizing committee invited the authors if they desired, to submit a paper version of their presentations. These papers constitute Part 5 of this book.

The book ends with a subject index and a list of symbols used commonly throughout the text. To facilitate the reading between chapters a common set of symbols was selected for use in each individual chapter. Very specific symbols used only in one chapter are defined in that chapter.

It is a pleasure to recognize here the effective and friendly help I received from the members of the organizing committee: L. de Backer, F. Correia, J. Ganoulis and G. de Marsily. They greatly simplified my task. At Colorado State University I could count again on the reliable talent of Mrs. Sandy Wittler for typing part of the manuscript and for the final assembly of the book and on Dr. T. Sanders, my office-mate for many years, to relieve me of some school tasks when I got pressed for time. As an editor I had a wonderful opportunity to become familiar with all the contributions and to interact with their authors. Without modesty, I'11 take credit for the selection of a most competent group to cover the broad subject of this book. They deserve praise too to have met (most of) my editorial demands and cooperated so willingly.

Fort Collins, Colorado December 1988 